\title{
Subjective Health Complaints and Self-Rated Health: Are Expectancies More Important Than Socioeconomic Status and Workload?
}

\author{
Eline Ree • Magnus Odeen • Hege R. Eriksen • Aage Indahl • \\ Camilla Ihlebak • Jørn Hetland • Anette Harris
}

Published online: 19 July 2013

(C) The Author(s) 2013. This article is published with open access at Springerlink.com

\begin{abstract}
Background The associations between socioeconomic status (SES), physical and psychosocial workload and health are well documented. According to The Cognitive Activation Theory of Stress (CATS), learned response outcome expectancies (coping, helplessness, and hopelessness) are also important contributors to health. This is in part as independent factors for health, but coping may also function as a buffer against the impact different demands have on health. Purpose The purpose of this study was to investigate the relative effect of SES (as measured by level of education), physical workload, and response outcome expectancies on subjective health complaints (SHC) and self-rated health, and if response outcome expectancies mediate the effects of education and physical workload on SHC and self-rated health.

Methods A survey was carried out among 1,746 Norwegian municipal employees (mean age 44.2, $81 \%$ females). Structural Equation Models with SHC and self-rated health as outcomes were conducted. Education, physical workload,
\end{abstract}

E. Ree $(\triangle) \cdot$ M. Odeen $\cdot$ H. R. Eriksen $\cdot$ A. Harris

Uni Health, Uni Research, P.O. Box 7810, 5020 Bergen, Norway

e-mail: eline.ree@uni.no

E. Ree $\cdot$ M. Odeen $\cdot$ A. Indahl

Clinic Physical Medicine and Rehabilitation, Vestfold Hospital

Trust, Stavern, Norway

H. R. Eriksen · A. Harris

Department of Health Promotion and Development,

Faculty of Psychology, University of Bergen, Bergen, Norway

C. Ihlebæk

Section of Public Health, ILP,

Norwegian University of Life Sciences, Ås, Norway

J. Hetland

Department of Psychosocial Science, Faculty of Psychology,

University of Bergen, Bergen, Norway and response outcome expectancies, were the independent 28 variables in the model.

Results Helplessness/hopelessness had a stronger direct effect on self-rated health and SHC than education and physical workload, for both men and women. Helplessness/ hopelessness fully mediated the effect of physical workload on SHC for men (0.121), and mediated $30 \%$ of a total effect of 0.247 for women. For women, education had a small but significant indirect effect through helplessness/hopelessness on self-rated health (0.040) and SHC (-0.040), but no direct effects were found. For men, there was no effect of education on SHC, and only a direct effect on self-rated health (0.134).

Conclusions The results indicated that helplessness/ hopelessness is more important for SHC and health than wellestablished measures on SES such as years of education and perceived physical workload in this sample. Helplessness/ hopelessness seems to function as a mechanism between physical workload and health.

Keywords Subjective health complaints - Coping · Helplessness $\cdot$ Hopelessness $\cdot$ Socioeconomic status · TomCats $\cdot$ Physical workload

\section{Introduction}

The presence of systematic differences in health between socioeconomic groups as measured by income, occupation and education is well documented $[1,2]$. The health gradient is not restricted to low-income countries, but is also present in countries with well-established welfare systems [3]. Compared with higher socioeconomic groups, the lower socioeconomic groups have a higher prevalence of poor self-reported health (subjective health complaints, self-rated general health, chronic pain, and disability), higher incidence of specific diseases, and higher rates of mortality [4]. 
Subjective health complaints (SHC) are often characterized by few if any objective findings [5], and there is a high prevalence of these complaints in the general population $[6$, 7]. SHC are also the main reasons for long-term sick leave and disability in Norway [8-10] and other western countries [11]. Self-rated general health is a well-validated and commonly used health indicator, and it is a strong predictor of future mortality and use of health services [12-15]. Individuals in lower socioeconomic groups report poorer self-rated health and more subjective health complaints compared to those in the higher socioeconomic groups [4, 16-19].

However, we still do not know all the mechanisms that might explain the association between socioeconomic status (SES) and health [20]. Occupational factors are important predictors for employees' health [21] and it has been suggested that physical and psychosocial demands and conditions at work may constitute important links between SES and health [19, 22-25]. Physical working conditions (e.g., physical strains in doing the job, monotony at work) have been shown to explain most of the social gradient in self-rated health among a representative sample of Swiss employees [23]. Similarly, in a cohort from Finland, heavy physical working conditions explained a large part of the socioeconomic inequalities in self-rated health [22]. However, the importance of control [22] and the relationship between effort and rewards $[25,26]$ have also been shown, although coping has been reported to be more important to health than control [27]. Coping are defined and measured in many different ways. The "ways of coping" model, which focuses on coping strategies, is one of the most influential models [28]. However, according to Ursin and Eriksen [29], the strategy chosen does not predict the internal state and thus it does not predict health. In their Cognitive Activation Theory of Stress (CATS) they argue that coping predicts relations to health and disease only when it is defined as positive response outcome expectancy.

The Cognitive Activation Theory of Stress [29] can be used to explain the association between coping and health, and the importance of coping for socioeconomic differences in health. Whenever an individual is faced with threats, challenges, or demands, an increase in arousal or activation will follow. If a person has established positive response outcome expectancies (The CATS definition of coping), this increase in activation is short and has a positive influence on health. If the individual expects that he or she will not cope with the situation or the demands, the activation may be sustained over time, which is associated with illness, disease and possible poor health. In CATS, response outcome expectancies may be positive (coping), negative (hopelessness), or the individual may have established no (helplessness) response outcome expectancy. There is no linear relationship between the challenges or demands the individual is faced with, and the increase in arousal. It is the individual's experience of the demands and the expectancies of the response outcome that is important for the sustained activation and the possible negative health effects [29]. Coping is shown to be an important predictor for socioeconomic differences in health $[16,30,31]$. Lower scores on the expectancy to cope are demonstrated among individuals with low socioeconomic status, both within and between countries [32]. High level of coping is associated with high social position and social success, in both humans and animals [33]. A large Swedish study, SLOSH [16], has used a newly developed scale to measure expectancies of coping as defined in CATS. In this study, coping was a better predictor for health than socioeconomic status, and the relationship between coping and SES was almost linear. These results might have important practical implications, as it is possible to alter individual's response outcome expectancies. If coping is a link between SES and health, increasing the individuals' expectancies of coping might help to reduce the social gradient in health. Individual differences in the expectancy and ability to cope with the demands faced in life in general and, more specifically, at the workplace, may also be important for how the work characteristics affect the employees [27, 34]. Employees with lower income report lower levels of coping and more obstacles in life [35]. However, coping seems to dampen the negative effects of low income. When individuals with low income report a high level of coping, their health and wellbeing is comparable with the higher income groups. Thus, high levels of coping might make it more likely for employees to manage the consequences of an adverse work environment. Previous studies have also found coping to be an important predictor for subjective health complaints [27, 34, 36, 37], and for self-rated general health $[16,38]$.

In the present study, education will be used as a measure of socioeconomic status. Education is a well-established measure of socioeconomic status in Norway. There are relatively small differences in income in different occupational status in this country, and education is more comparable across different countries than occupational status and income [39]. Although schooling is an integral part of society in Norway, research has shown that there is a linear relationship between higher education and better health [3].

The aim of this study is to explore the contribution of socioeconomic status, physical workload, and response outcome expectancies in explaining subjective health complaints and general health. It is assumed that socioeconomic status, physical workload, and response outcome expectancies are associated with health. We hypothesize that response outcome expectancies will be a stronger predictor for SHC and self-rated health than education and physical workload. Furthermore, we hypothesize that response outcome expectancies will mediate the effect of education on SHC and self-rated health, and that response outcome expectancies will mediate the effect of physical workload on SHC and self-rated health.

Women generally report more subjective health complaints than men [40], and there might be different mechanisms that 
affect health and health complaints in men and women. Therefore, we will explore the hypotheses across gender.

\section{Methods}

Participants and Procedure

The sample consisted of 1,746 Norwegian municipality employees $(81 \%$ females, mean age $=44.2$ years $(S D=11.5))$ recruited from two municipalities in Norway as part of a large randomized controlled trial; "atWork" [41]. All employees above 18 years of age in the municipalities of Kongsberg and Horten, Norway, were invited to participate in the study. At the start of the study, it was estimated to be approximately 1,500 municipality employees in Kongsberg and 2,000 in Horten, giving a response rate of approximately $50 \%$. The municipalities have a population about 25,000 each. $450(27 \%)$ of the respondents had 1-12 years of schooling, 534 (32\%) of the respondents had 13-15 years of schooling, and $699(41 \%)$ of the respondents had more than 15 years of schooling.

The study followed the Helsinki declaration, and was approved by the Norwegian regional ethics committee in western Norway (REK-vest, ID 6.2008.117), the Norwegian social science data services recommended the study (NSD, ID 18997), as well as the privacy authority at the National Hospital (Rikshospitalet, ID 08/2421). All employees gave their informed consent before participating in the study.

\section{Instruments}

\section{Outcome Variables}

Subjective health complaints were measured by the subjective health complaints inventory [5]. It consists of 29 items of common health complaints experienced during the last 30 days, where the items are rated on a four point scale from $0=$ "no complaints" to $3=$ "serious complaints". The items are categorized into five factors: musculoskeletal pain $(\alpha=0.78)$, pseudoneurology $(\alpha=0.75)$, gastrointestinal problems $(\alpha=0.70)$, and allergy $(\alpha=0.57)$. In the present study, the subscale "flu" was excluded from the analyses because of seasonal variation. Prior to analysis, sum scores representing the remaining four subscales of subjective health complaints were computed.

Self-rated health was measured by a single question: "How will you generally rate your health?" Respondents were given five response options, from 1 = "very good" to $5=$ "very poor". The scale was reversed so that higher scores indicate better health.

\section{Predictor Variables}

Education was used as a measure of socioeconomic status and was measured by the question "how many years of schooling/studies have you completed in total? (count the number of years from the first year of primary/elementary school)".

Perceived physical workload was measured by the question "do you have heavy/repetitive work?" with a ten point scale ranging from $0=$ "not at all" to $10=$ "very heavy/repetitive".

Response outcome expectancy was measured by six items from The Theoretically Originated Measure of the Cognitive Activation Theory of Stress (TomCats), which is developed at Uni Health in Norway [16]. It is a newly developed scale, designed to measure response outcome expectancies in CATS [29]. The scale consists of three factors, which represent the three response outcome expectancies in CATS: positive expectancy/coping (one item), no expectancy/helplessness (three items) and negative expectancy/hopelessness (three items). The three factors consists of the following statements: [1] Coping: "I can solve most difficult situations with a good result" (CATS7), [2] Helplessness: "I really don't have any control over the most important issues in my life" (CATS4), "all my attempts at changing my life are meaningless" (CATS1), "I wish I could change my life, but it's not possible" (CATS6), and [3] Hopelessness: "all my attempts at making things better just make them worse" (CATS2), "It's better that others try to solve my problems than for me to mess things up and make them worse" (CATS5), "I would have been better off if I didn't try so hard to solve my problems" (CATS3). All items were rated on a five point scale from $1=$ "not true at all" to $5=$ "completely true". In a previous study of a Swedish population [16], the scale proved to have high reliability and a clear factor structure.

In the present study, the coping item did not correlate significantly with the other variables in the study, and was therefore not included in the analyses. Furthermore, helplessness and hopelessness are treated as one single factor due to results of factor and reliability analyses. The Chronbach's alpha of the helplessness/hopelessness construct in the present study is 0.77 .

\section{Statistics}

AMOS version 20.0 was used to perform structural equation modeling to test the hypothesized models. Maximum likelihood estimation was used to estimate all models. Initially, measurement models of the study constructs were estimated. Subsequently, total, direct, and indirect effects between the 
study variables were tested in a structural model. The direct paths from physical workload and education to subjective health complaints and self-rated health were estimated in the model, as well as the indirect paths mediated by helplessness/hopelessness. Monte Carlo Estimation was used to examine the significance of the indirect effects [42]. The following indices were used to evaluate the goodness of fit of the models: $\chi^{2}$ statistics, Comparative Fit Index (CFI) and Root-Mean-Square Error Approximation (RMSEA). According to Brown and Cudeck [43], a RMSEA value less than 0.05 indicates a good fit, while values as high as 0.08 represents a fair fit. A CFI above 0.90 is considered to be representative of a well-fitting model [44]. In the analysis, the different models were also compared by evaluating the change in chi-square relative to the change in degrees of freedom as all models were nested.

The Full-Informational Maximum Likelihood (FIML) method, within the AMOS 20.0 software, was used to handle missing cases. This method has shown to produce unbiased parameter estimates and standard errors, when data are missing at random [45]. In FIML, missing values are imputed by estimating the likelihood functioning for each individual based on the variables present in the model.

The subjective health complaint factors and the helplessness/hopelessness factor showed a positively skewed distribution. This was expected, as a low score on these variables represents a normal trend in the population. To correct for non-normality, we transformed these variables with logarithmic transformations. However, as this did not affect the results of the analyses, we chose to use the original non-transformed variables in the final analyses and presentation of the results.

\section{Results}

The mean, standard deviation, and inter-correlations for study variables are shown in Table 1 .

\section{Structural Equation Modeling}

By imposing correlations between the study constructs, an overall measurement model of self-rated health, SHC, education, physical workload and helplessness/hopelessness were tested. In the model, subjective health complaints and helplessness/hopelessness were modeled as latent constructs, while self-rated health, education and physical workload were estimated by single observed variables. In order to test for the possibility to apply a multi group analysis, a model freely measuring all parameters $\left(\chi^{2}=499.37, d f=116\right)$ was compared with a model constraining all measurement weights to be equal across gender $\left(\chi^{2}=532.44, d f=124\right)$. The restricted model did, however, resolve in a significant increase in Chi-square $\left(\Delta \chi^{2}=33.07, \Delta d f=8, p<0.001\right)$

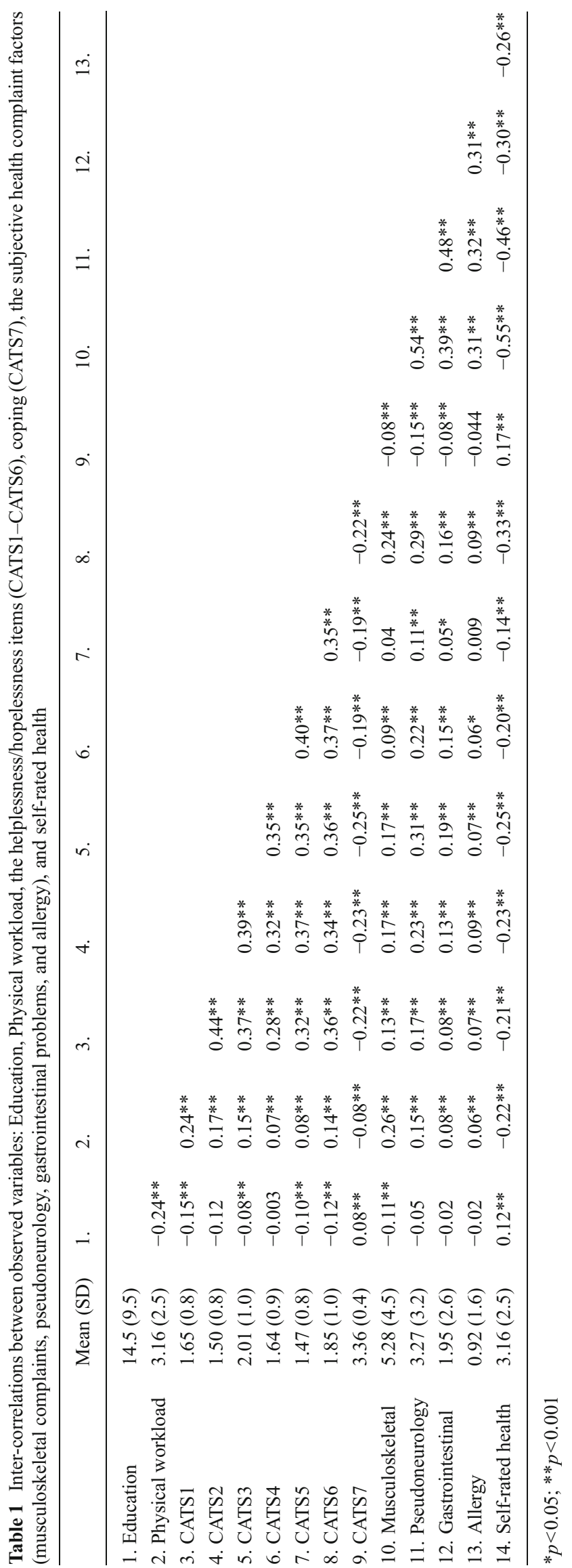


indicating a different measurement model across gender, excluding the use of multi group analysis. Consequently, all subsequent analyses were performed separately for women and men.

Table 2 shows the fit of the measurement models and the structural models separately for women and men. In both groups, men and women, the measurement model showed an adequate fit $\left(\chi^{2}(58)=102.78, \mathrm{CFI}=0.95, \mathrm{RMSEA}=0.049\right.$; $\chi^{2}(58)=396.56, \mathrm{CFI}=0.91, \mathrm{RMSEA}=0.064$, respectively). Moreover, acceptable factor loadings in the range from 0.42 to 0.78 were found for all the latent constructs in the models.

As shown in Table 3, subjective health complaints had a substantial negative association with self-rated health in both genders, while the correlation with education was only significant among women. There were significant positive correlations between subjective health complaints, physical workload and helplessness/hopelessness for both men and women, while helplessness/hopelessness had a significant negative correlation with education and self-rated health. The correlation between helplessness/hopelessness and the other constructs varied from -0.16 to -0.38 in the group of women, and from -0.16 to -0.48 in the group of men.

As shown in Table 2, when estimating the structural model with imposed direct effects without mediational effects in the female group, the fit to the data was poorer as compared to the measurement model $(\mathrm{RMSEA}=0.075 ; \mathrm{CFI}=0.88)$. In the direct effect model, there was a significant path between education and self-rated health, but the path between education and subjective health complaints was not significant. When including a mediational path through helplessness/hopelessness, the fit improved $(\mathrm{RMSEA}=0.064 ; \mathrm{CFI}=0.91)$. As hypothesized, the path from education to self-rated health was no longer significant. Therefore, a final model without the paths from education to SHC and self-rated health was estimated. Excluding these paths did not cause a significant increase in $\chi^{2}(\Delta d f=2$; $\Delta \chi^{2}=1.35$, n.s.) indicating that this model is superior to the initial model based on the principal of parsimony. The final model showed good fit to the data (RMSEA $=0.063$; $\mathrm{CFI}=0.91)$. The paths in the structural model are presented in Fig. 1.

As shown in Table 4, there was a significant positive total effect between physical workload and subjective health complaints $(\beta=0.247)$ in the final model for women. A direct effect of $0.173(70 \%)$ and an indirect effect of $0.074(30 \%)$ was found. In order to test the significance of the indirect effect, a Monte Carlo calculation was conducted [42], showing that the indirect effect was significant (95\% CI, $0.01-$ $0.03)$. There was a significant positive total effect between physical workload and self-rated health $(\beta=-0.238)$. A direct effect of $-0.163(68 \%)$ and an indirect effect of -0.074 (32\%) were found between these constructs. The Monte Carlo calculation showed that the indirect effect was significant (95\% CI, 0.02-0.03). There was a significant positive but small total effect between education and self-rated health $(\beta=0.040)$. While no significant direct effect was found, a significant indirect path of 0.040 (100\% of the total effect) was revealed. A Monte Carlo calculation showed that the indirect effect was significant $(95 \% \mathrm{CI}, 0.00-0.02)$. The

Table 2 Fit indices and model comparison for tested models

\begin{tabular}{|c|c|c|c|c|c|c|c|}
\hline \multirow[t]{2}{*}{ Model } & \multicolumn{4}{|c|}{ Model fit } & \multicolumn{3}{|c|}{ Model comparison } \\
\hline & $\chi^{2}$ & $d f$ & CFI & RMSEA & Comparison & $\Delta \chi^{2}$ & $\Delta d f$ \\
\hline \multicolumn{8}{|l|}{ Total } \\
\hline M1: Measurement model & 449.92 & 58 & 0.92 & 0.057 & - & - & - \\
\hline M2: Direct effect model & 635.40 & 60 & 0.88 & 0.068 & M1-M2 & $185.48 *$ & 2 \\
\hline M3: Mediation model & 449.92 & 58 & 0.92 & 0.057 & M2-M3 & $185.48^{*}$ & -2 \\
\hline M4: Final model & 454.08 & 60 & 0.92 & 0.056 & M3-M4 & 4.16 & 2 \\
\hline \multicolumn{8}{|l|}{ Women } \\
\hline M1: Measurement model & 396.56 & 58 & 0.91 & 0.064 & - & - & - \\
\hline M2: Direct effect model & 537.33 & 60 & 0.88 & 0.075 & M1-M2 & $140.77 *$ & 2 \\
\hline M3: Mediation model & 396.56 & 58 & 0.91 & 0.064 & M2-M3 & $140.77 *$ & -2 \\
\hline M4: Final model & 397.91 & 60 & 0.91 & 0.063 & M3-M4 & 1.35 & 2 \\
\hline \multicolumn{8}{|l|}{ Men } \\
\hline M1: Measurement model & 102.78 & 58 & 0.95 & 0.049 & - & - & - \\
\hline M2: Direct effect model & 154.30 & 60 & 0.89 & 0.07 & M1-M2 & $51.52 *$ & 2 \\
\hline M3: Mediation model & 102.78 & 58 & 0.95 & 0.049 & M2-M3 & $51.52 *$ & -2 \\
\hline M4: Final model & 105.95 & 62 & 0.95 & 0.047 & M3-M4 & 3.17 & 4 \\
\hline
\end{tabular}

$C F I$ comparative fit index, RMSEA root-mean-square error approximation $* p<0.001$ 
Table 3 Correlation between latent and observed study variables in the measurement model (CFI) by gender

\begin{tabular}{|c|c|c|c|c|c|}
\hline & Mean (SD) & 1. & 2. & 3. & 4. \\
\hline \multicolumn{6}{|l|}{ Women } \\
\hline 1. Education (SES) & $14.50(2.93)$ & & & & \\
\hline 2. Physical workload & $3.23(2.51)$ & $-0.22 * *$ & & & \\
\hline 3. Helplessness/hopelessness & $10.02(3.60)$ & $-0.16^{* *}$ & $0.24 * *$ & & \\
\hline 4. Self rated health & $3.02(0.79)$ & $0.11 * *$ & $-0.24 * *$ & $-0.38 * *$ & \\
\hline 5. Subjective health complaints & $12.63(9.85)$ & $-0.08 *$ & $0.25^{* *}$ & $0.38 * *$ & $-0.68 * *$ \\
\hline \multicolumn{6}{|l|}{ Men } \\
\hline 1. Education (SES) & $14.48(3.41)$ & & & & \\
\hline 2. Physical workload & $2.81(2.34)$ & $-0.33 * *$ & & & \\
\hline 3. Helplessness/hopelessness & $10.59(3.74)$ & $-0.16^{*}$ & $0.25 * *$ & & \\
\hline 4. Self rated health & $3.00(0.76)$ & $0.20 * *$ & $-0.12^{*}$ & $-0.38 * *$ & \\
\hline 5. Subjective health complaints & $10.29(9.18)$ & -0.12 & $0.16^{*}$ & $0.48 * *$ & $-0.52 * *$ \\
\hline
\end{tabular}

${ }^{* *} p<0.001 ; * p<0.05$

squared multiple correlations $\left(R^{2}\right)$ in the final model were 0.177 for SHC and 0.171 for self-rated health.

As shown in Table 2, the direct effect model was poorer as compared to the measurement model (RMSEA $=0.070$; $\mathrm{CFI}=0.89$ ) in the group of men. In this model, there was a significant positive path from physical workload to SHC, while the paths from education to helplessness and subjective health complaints and from physical workload to selfrated health were not significant. When including a mediational path through helplessness/hopelessness, the fit improved (RMSEA $=0.049 ; \mathrm{CFI}=0.95$ ). As hypothesized, the path from physical workload to SHC was no longer significant. Therefore, a final model without the insignificant paths was estimated. Excluding these paths did not cause a significant increase in $\chi^{2}\left(\Delta d f=4 ; \Delta \chi^{2}=3.17\right.$, n.s.), indicating that this model is superior to the initial model based on the principal of parsimony. The final model showed good fit to the data (RMSEA $=0.047 ; \mathrm{CFI}=0.95$ ). The paths in the structural model are presented in Fig. 2.

As shown in Table 4, there was a significant positive total effect between education and self-rated health $(\beta=0.134)$ in the final model for men. No significant indirect effect was found between these constructs. The total effect between physical workload and subjective health complaints was significantly positive $(\beta=0.121)$. While no significant direct effect was found, a significant indirect path of $0.121(100 \%$ of the total effect) was revealed. A Monte Carlo calculation showed that the indirect effect was significant $(95 \% \mathrm{CI}, 0.02$ $0.07)$. The squared multiple correlations $\left(R^{2}\right)$ in the final model were 0.232 for SHC and 0.154 for self-rated health.

\section{Discussion}

The central purpose of this study was to investigate whether response outcome expectancies are a stronger predictor for SHC and self-rated health than education and physical workload, and if response outcome expectancies mediate the effects of socioeconomic status and physical workload on SHC and self-rated health. The results confirmed the first hypothesis of the paper, as response outcome expectancies were a stronger predictor than education and perceived physical workload for subjective health complaints and self-rated general health. This result is similar to a study from Sweden, which used the same scale to measure response outcome expectancies as the current study [16]. Coping was a stronger predictor for self-rated health than both subjective and objective social status in the Swedish study [16]. The authors concluded that coping was one of the mechanisms underlying the association between socioeconomic status and health.
Fig. 1 Parameter estimates for final model in women. The circles represent latent variables. The squares represent observed variables. All path coefficients are significant at $p<0.01$

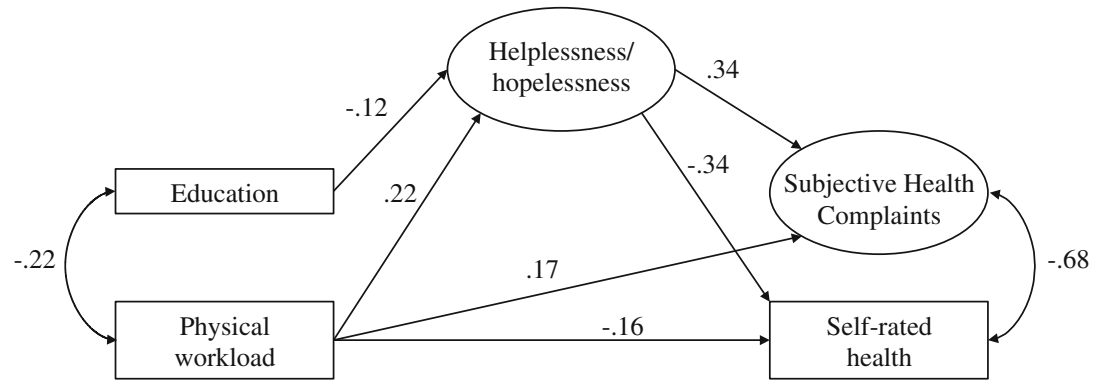


Table 4 Standardized total, direct and indirect effects of education, physical workload and helplessness/hopelessness on subjective health complaints (SHC) and self-rated health for men and women

\begin{tabular}{|c|c|c|c|c|c|c|}
\hline & \multicolumn{3}{|l|}{ Women } & \multicolumn{3}{|l|}{ Men } \\
\hline & Helplessness/hopelessness & SHC & Self-rated health & Helplessness/ hopelessness & $\mathrm{SHC}$ & Self-rated health \\
\hline \multicolumn{7}{|l|}{ Total effects } \\
\hline Education (SES) & -0.116 & -0.040 & 0.040 & - & - & 0.134 \\
\hline Physical workload & 0.217 & 0.247 & -0.238 & 0.251 & 0.121 & - \\
\hline Helplessness/hopelessness & - & 0.344 & -0.342 & - & 0.481 & -0.358 \\
\hline \multicolumn{7}{|l|}{ Direct effects } \\
\hline Education (SES) & -0.116 & - & - & - & - & 0.134 \\
\hline Physical workload & 0.217 & 0.173 & -0.163 & 0.251 & - & - \\
\hline Helplessness/hopelessness & - & 0.344 & -0.342 & - & 0.481 & -0.358 \\
\hline \multicolumn{7}{|l|}{ Indirect effects } \\
\hline Education (SES) & - & -0.040 & 0.040 & - & - & - \\
\hline Physical workload & - & 0.074 & -0.074 & - & 0.121 & - \\
\hline Helplessness/hopelessness & - & - & - & - & - & - \\
\hline
\end{tabular}

All effects $p<0.001$

The present study partially supports the hypothesis that coping, or in this case helplessness/hopelessness, might function as a mechanism between socioeconomic status and health, as helplessness/hopelessness fully mediated the effect of education on self-rated health and SHC for the female group. However, the effect of education was small, and for men it had no significant effect on SHC, and only a direct effect on self-rated health. Ihlebæk et al. [7] also found that education was a significant predictor for SHC in women, but not in men. Furthermore, in line with the present study, Ihlebæk et al. [7] found that physical workload was significantly related to SHC for both genders. However, the full model in that study, with several predictors such as lifestyle, work-related factors, etc., explained little of the variance in SHC. The authors suggested that coping and other psychological factors might be of stronger importance for SHC [7].

In the present study, helplessness/hopelessness was a stronger predictor for SHC and self-rated health than education and physical workload. Furthermore, helplessness/hopelessness seemed to be a mechanism between physical workload and health, as it partially mediated the effect of physical workload on SHC and self-rated health for women, and fully mediated the effect of physical workload on SHC for men. This is in accordance with a previous study that found unfavorable coping strategies to be related to negative work characteristics and poor health [46]. The results of the present study are also in line with a study by Karademas et al. [47], where helplessness had both a direct effect on subjective health, and an indirect effect through certain coping strategies. In the present study, the association between physical workload and the health outcomes were stronger in the female group than in the male group. The results are in accordance with a study of anesthesiology students, were female students more often reported higher concentration demands and limited possibilities to control work compared to male students [48]. The present study indicates that the effect of physical workload on SHC is partially due to individual's lack of coping, especially in men.

The results may be explained within the framework of CATS [29], where the individual's expectancy of being able to cope with the demands and challenges he or she encounters in the workplace are more important for the employees' health than the demands or objective work characteristics themselves. However, the subjective perception of physical workload does not necessarily correspond with the actual physical workload. Research has shown that correlations between subjective perceptions of work conditions and the
Fig. 2 Parameter estimates for final model in men. The circles represent latent variables. The squares represent observed variables. All path coefficients are significant at $p<0.01$

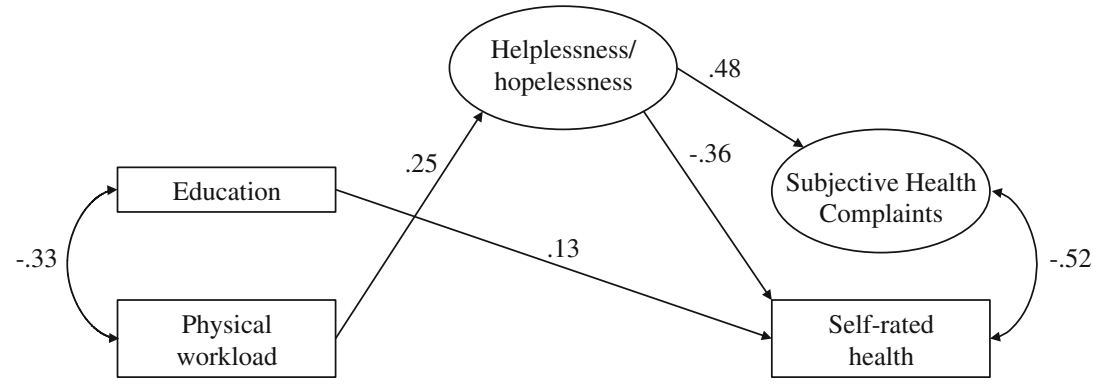


actual objective work conditions tend to be weak [49, 50]. Christie and Barling [30] suggest that coping and the work environment are dynamic and responsive to each other. In their longitudinal study, individuals who reported lower levels of coping at baseline increasingly perceived more work stressors and health problems over time. The same pattern yielded for individuals who reported more work stressors at baseline, as these perceived less degree of coping over time than those who initially reported less work stressors. In line with the present study, these findings make it reasonable to assume that poor health might partly be a product of individual's expectancies of coping with difficulties.

The main strength of the present study is that it is based on a large and representative sample of Norwegian municipality employees, which provides a good basis for generalization of the results to other worksites. The sample is diverse with regard to work type and workplace size, which reduces the possibility of effects of localization or group specific effects. However, a response rate of about $50 \%$ may limit the validity of the findings. Even though considerable efforts were made to improve the response rate by providing information to the employees about the project, it remained low. The high predominance of women in the sample (about $80 \%$ ) represents characteristics of the population in general, as $69 \%$ of all public sector employees are women, with the majority working in the municipalities [51]. In the two participating municipalities, $79 \%$ and $68 \%$ of the employees are women. However, caution should be made when generalizing to private sector employees.

The majority of the participants in this study had higher university education, and the sample was generally highly educated. Thus, the significance of education on health and the relationship between education and helplessness/ hopelessness might have been undermined due to small variance. Further studies should investigate the relationship between the variables in a more heterogeneous sample. In addition, the inclusion of more items and preferably validated scales of workload and work characteristics would provide more reliable conclusions regarding the relationship between work characteristics, coping, socioeconomic status, and health.

Although several of the results in the paper were statistically significant, the coefficients and effect sizes were relatively small. This may be a consequence of the large sample size of the study, as large samples make it more likely to achieve statistical significance even with small effect sizes [52]. However, a large sample increases the likelihood that the results are in accordance with the actual population value [52], and even small effect sizes might have important practical significance. For example, as it is possible to influence and alter individuals' response outcome expectancies, coping has important implications for interventions. Thus, for jobs where it is difficult to remove the objective work stressors, interventions should focus on improving the employees' expectancies of coping. Empowerment interventions aimed at strengthening employees' positive response outcome expectancies may enable the employees to manage the possible consequences of facing a tough work environment, and thereby improve the employees' health and reduce health inequalities in the population. According to Rappaport [53], empowerment involves both a subjective perception of personal control, and a sufficient degree of real social impact. Thus, interventions should focus both on strengthening the employees' positive response outcome expectancies (individual level), and to facilitate and create opportunities to cope (organizational level). At the individual level, Cognitive Behavioral Therapy (CBT) can be used to increase employees' positive response outcome expectancies. The aim of CBT at an individual level is to challenge and change individuals' unhelpful thought patterns in a positive direction by focusing on his or hers previous coping experiences, and gaining new coping experiences through behavioral experiments. In line with CATS, the treatment is based on the belief that coping generalizes, and the goal is for low-coping individuals to obtain expectancies of coping. Examples of such empowerment interventions at the organizational level are individual adjustment of tasks and goals, giving the employees opportunities to participate in goal setting, manageable sub-goals, social support from supervisors and co-workers, and acknowledgement and feedback concerning the employees work achievements.

Acknowledgments The study was funded by the South-Eastern Norway Regional Health Authority and by the Hospital at Vestfold, Stavern. Thanks to Erik Lindh for coordinating the project. Thanks to Britt Øvregård and Berit Borge at the municipalities for help in the project. Thanks to Nina Konglevoll for quality assurance and data punching. Also, thanks to Holger Ursin for good discussion and carefully reading of the manuscript, and to Kyrre Breivik for discussions of statistical issues.

Conflict of interest statement None declared.

Open Access This article is distributed under the terms of the Creative Commons Attribution License which permits any use, distribution, and reproduction in any medium, provided the original author(s) and the source are credited.

\section{References}

1. Adler NE, Boyce T, Chesney MA, Cohen S, Folkman S, Kahn RL, et al. Socioeconomic status and health. The challenge of the gradient. Am Psychol. 1994;49(1):15-24.

2. Torgersen TP, Giæver Ø, Stigen OT. Developing an intersectoral national strategy to reduce social inequalities in health. The Norwegian Case. Oslo: The Norwegian Directorate of Health and Social Affairs; 2007.

3. Kunst AE, Bos V, Lahelma E, Bartley M, Lissau I, Regidor AM, et al. Trends in socioeconomic inequalities in self-assessed health in 10 European countries. 34. 2005:295-305. 
4. Van Lenthe FJ, Schrijvers CTM, Droomers M, Joung IMA, Louwman MJ, Mackenbach JP. Investigating explanations of socio-economic inequalities in health. The Dutch GLOBE study. Eur J Public Health. 2004;14:63-70.

5. Eriksen HR, Ihlebæk C, Ursin H. A scoring system for subjective health complaints (SHC). Scand J Public Health. 1999;1:63-72.

6. Indregard A-M, Ihlebæk C, Eriksen H. Modern Health worries, subjective health complaints, health care utilization, and sick leave in the Norwegian working population. International Journal of Behavioral Medicine. 2012:1-7.

7. Ihlebæk C, Eriksen HR. Occupational and social variation in subjective health complaints. Occup Med. 2003;53:270-8.

8. Ihlebæk C, Brage S, Eriksen HR. Health Complaints and Sickness absence in Norway, 1996-2003. Occup Med. 2007;57:43-9.

9. NAV. Sykefraværstilfeller 2. kv 2001-2010. Diagnose og kjønn. Antall og prosent Oslo2010 [updated 21.09; cited 2010 07.11]. Available from: http://www.nav.no/251592.cms.

10. Tellnes G, Svendsen K, Bruusgaard D, Bjerkedal T. Incidence of sickness certification. Proposal for use as a health status indicator. Scand J Prim Health Care. 1989;7(2):111-7.

11. Waddell G, Burton AK. Is work good for your health and wellbeing? London: TSO; 2006

12. DeSalvo KB, Bloser N, Reynolds K, He J, Muntner P. Mortality prediction with a single general self-rated health question. J Gen Intern Med. 2006;21(3):267-75.

13. Miilunpalo S, Vuori I, Oja P, Pasanen M, Urponen H. Self-rated health status as a health measure: the predictive value of selfreported health status on the use of physician services and on mortality in the working-age population. J Clin Epidemiol. 1997;50(5):517-28.

14. Heistaro S, Jousilahti P, Lahelma E, Vartiainen E, Puska P. Self rated health and mortality: a long term prospective study in eastern Finland. J Epidemiol Community Health. 2001;55:227-32.

15. Idler EL, Benyamini Y. Self-rated health and mortality: a review of twenty-seven community studies. J Heal Soc Behav. 1997;38(1):21-37.

16. Odéen $\mathrm{M}$, Westerlund $\mathrm{H}$, Theorell $\mathrm{T}$, Leineweber $\mathrm{C}$, Eriksen $\mathrm{H}$, Ursin H. Expectancies, socioeconomic status, and self-rated health: use of the simplified TOMCATS questionnaire. International Journal of Behavioral Medicine. 2012:1-10.

17. Huisman M, van Lenthe F, Mackenbach J. The predictive ability of self-assessed health for mortality in different educational groups. Int J Epidemiol. 2007;36(6):1207-13.

18. Brekke M, Hjortdahl P, Kvien TK. Severity of musculoskeletal pain: relations to socioeconomic inequality. Soc Sci Med. 2002;54(2):221-8.

19. Borg V, Kristensen TS. Social class and self-rated health: can the gradient be explained by differences in life style or work environment? Soc Sci Med. 2000;51:1019-30.

20. Adler NE, Snibbe AC. The role of psychosocial processes in explaining the gradient between socioeconomic status and health. Curr Dir Psychol Sci. 2003;12(4):119-23.

21. Karasek R, Theorell T. Healthy work: stress, productivity and the reconstruction of working life. New York: Basic; 1990.

22. Kaikkonen R, Rahkonen O, Lallukka T, Lahelma E. Physical and psychosocial working conditions as explanations for occupational class inequalities in self-rated health. Eur J Public Health. 2009;19(5):458 63. PubMed PMID: WOS:000270218100008. English.

23. Bauer GF, Huber CA, Jenny GJ, Muller F, Hammig O. Socioeconomic status, working conditions and self-rated health in Switzerland: explaining the gradient in men and women. Int J Public Health. 2009;54(1):23-30. PubMed PMID: WOS:000263077000005. English.

24. Mehlum IS, Kristensen P, Kjuus H, Wergeland E. Are occupational factors important determinants of socioeconomic inequalities in musculoskeletal pain? Scand J Work Environ Health. 2008;34(4):250-9.
25. Siegrist J, Marmot MG. Health inequalities and the psychosocial environment-two scientific challenges. Soc Sci Med. 2004;58: 1463-73.

26. Gillen M, Yen IH, Trupin L, Swig L, Rugulies R, Mullen K, et al. The association of socioeconomic status and psychosocial and physical workplace factors with musculoskeletal injury in hospital workers. Am J Ind Med. 2007;50(4):245-60.

27. Eriksen HR, Ursin H. Subjective health complaints: is coping more important than control? Work Stress. 1999;13(3):238-52.

28. Lazarus R, Folkman S. Stress, appraisal and coping. New York: Springer; 1984

29. Ursin H, Eriksen HR. The cognitive activation theory of stress. Psychoneuroendocrinology. 2004;29:567-92.

30. Christie AM, Barling J. Disentangling the indirect links between socioeconomic status and health: the dynamic roles of work stressors and personal control. J Appl Psychol. 2009;94(6):1466-78.

31. Kristenson M, Eriksen HR, Sluiter JK, Starke D, Ursin H. Psychobiological mechanisms of socioeconomic differences in health. Soc Sci Med. 2004;58:1511-22.

32. Kristenson M. Socio-economic position and health: the role of coping. In: Siegrist J, Marmot M, editors. Social inequalities in health new evidence and policy implications. New York: Oxford University Press; 2006. p. 127-51.

33. Eriksen HR, Ursin H. Social inequalities in health: biological, cognitive and learning theory perspectives. Norsk Epidemiol. 2002;12(1):33-8.

34. Olff M, Brosschot JF, Godaert G. Coping styles and health. Personal Individ Differ. 1993;15(1):81-90.

35. Lachman ME, Weaver SL. The sense of control as a moderator of social class differences in health and well-being. J Personal Soc Psychol. 1998;74(3):763-73.

36. Ruchkin VV, Eisemann M, Hägglöf B. Coping styles and psychosomatic problems: are they related? Psychopathology. 2000;33(5):2359.

37. Eriksen HR, Olff M, Ursin H. The CODE: a revised battery of coping and defense and its relations to subjective health. Scand J Psychol. 1997;38:175-82.

38. Kristenson M, Olsson AG, Kucinskiene Z. Good self-rated health is related to psychosocial resources and a strong cortisol response to acute stress: The LiVicordia study of middle-aged men. Int J Behav Med. 2005;12(3):153-60. PubMed PMID: ISI:000231366300004. English.

39. Valkonen T. Adult mortality and level of education: a comparison of six countries. In: Fox J, editor. Health inequalities in European countries. Aldershot: Gower; 1989. p. 142-60.

40. Ihlebæk C, Eriksen HR, Ursin H. Prevalence of subjective health complaints (SHC) in Norway. Scand J Public Health. 2002;30:20 9.

41. ClinicalTrials.gov. Ibedrift - a trial comparing a new approach to musculoskeletal pain consisting of education and peer involvement to treatment as usual: ClinicalTrials.gov; 2008 [cited 2008 25]. Available from: http://clinicaltrials.gov/ct2/show/NCT00741650.

42. Selig JP, K.J. P. Monte Carlo method for assessing mediation: an interactive tool for creating confidence intervals for indirect effects 2008 [cited 2012 12.04.13]. Available from: http:// quantpsy.org/.

43. Brown MW, Cudeck R. Alternative ways of assessing model fit. In: Bollen KA, Long JS, editors. Testing structural equation models. Newbury Park, CA: Sage; 1993. p. 445-55.

44. Bentler PM. EQS structural equations program manual. Los Angeles: BMDP Statistical Software; 1992.

45. Roth PL. Missing data: a conceptual review for applied psychologists. Personnel Psychology. 1994;47:537-61.

46. Schreuder JAH, Roelen CAM, Groothoff JW, van der Klink JJL, Mageroy N, Pallesen S, et al. Coping styles relate to health and work environment of Norwegian and Dutch hospital nurses: a 
comparative study. Nurs Outlook. 2012;60(1):37-43. PubMed PMID: WOS:000299303200007. English.

47. Karademas EC, Hondronikola I. The impact of illness acceptance and helplessness to subjective health, and their stability over time: a prospective study in a sample of cardiac patients. Psychol Health Med. 2010;15(3):336-46. PubMed PMID: ISI:000277772000007. English.

48. Kinzl JF, Traweger C, Trefalt E, Riccabona U, Lederer W. Work stress and gender-dependent coping strategies in anesthesiologists at a university hospital. J Clin Anesth. 2006;19:334-8.

49. Davis KG, Heaney CA. The relationship between psychosocial work characteristics and low back pain: underlying methodological issues. Clin Biomech. 2000;15(6):389-406.
50. Veenhoven R. Why social policy needs subjective indicators. Assess Qual Life Living Cond Guide Natl Policy. 2002;11:33-45.

51. Barne- likestillings- og inkluderingsdepartementet. Meld. St. 6 (2010 2011). Melding til Stortinget: Likestilling for likelønn. In: Barne- 1-oi, editor. Oslo: Barne-, likestillings- og inkluderingsdepartementet; 2010.

52. Aarø LE. Fra spørreskjemakonstruksjon til multivariat analyse av data: En innføring i survey-metoden. 2nd ed. Bergen: Universitetet i Bergen; 2007.

53. Rappaport J. Terms of empowerment/exemplars of prevention: toward a theory for community psychology. Am J Community Psychol. 1987;15(2):121-48. 